\title{
Out of Darkness
}

\section{Shedding Light on End-of-life Care}

I $\mathrm{n}$ the difficult and often poorly lit terrain encountered at the end of life, how do we as health care professionals find our way? More importantly, how do we help our patients find their way? The end of life has received much attention in the popular media ${ }^{1,2}$ and in the medical community recently. This interest arises, in part, from patient and family member concerns about what they have witnessed, endured, or may yet experience regarding end-of-life care. In addition, difficult topics, such as physician-assisted suicide, have contributed to public and professional interest.

In this issue of the Journal, two papers address issues related to the end of life. Tierney and colleagues present data showing that patients' satisfaction with primary care doctors and clinic visits does not suffer when advance directive discussions occur. ${ }^{3}$ In fact, their data indicate that satisfaction improves. This was a carefully done, prospective cohort study that focused on patients who were older or sicker, patients for whom these issues are more likely to be relevant. As the authors acknowledge, a limitation of the study is that the conversations were not directly observed. Therefore, little is known about the content or quality of these interactions, and it is possible that superior physician communication skills confounded the results.

The Tierney findings are interesting, but a growing body of evidence suggests that advance directives, when approached in the conventional way, have limited utility. Quantitative studies have documented the extent to which advance directives are discussed, completed, and available when needed, and whether they have any effect on actual treatment decisions. ${ }^{4-7}$ The conclusion is that advance directives do not, in general, accomplish their goals. ${ }^{6}$ Accordingly, some authors have suggested modifying the objectives of advance care planning. ${ }^{8}$

Qualitative studies that elicit patients' perspectives have made important contributions to thinking differently about advance care planning. In a recent issue of the Journal, Rosenfeld and colleagues examined the perspectives of elderly patients on the matter of end-of-life decision making. ${ }^{9}$ One finding was that these patients wanted discussions about the end of life to focus on acceptable health states and valued life activities rather than preferences for specific treatment interventions. Other qualitative studies have similarly identified alternative goals for advance care planning, including facing death, relieving the burden on others, and strengthening relationships. ${ }^{10,11}$ The insights generated by these qualitative studies came from listening to patients. In addition to challenging the conventional approach, results from these studies offer ideas about how to modify what we say and do to make advance care planning more helpful and relevant for patients and family members.
Also in this issue of the Journal, Curtis and colleagues report the findings of their qualitative study to discover the skills necessary for doctors to provide high quality end-oflife care. ${ }^{12}$ Patients and family members, as well as health care professionals, identified 12 different domains and 55 specific components of physicians' skill for providing endof-life care. As noted in the paper, neither the investigators themselves nor their expert consultants anticipated all of the domains and components named by those interviewed. Furthermore, not all of the domains presented in the Curtis paper are reflected in a consensus statement by leaders in the field that addressed quality of care at the end of life. ${ }^{13}$ Specifically, the domains of team communication and coordination, patient education, and personalization do not seem to be addressed in the consensus statement, while the domains of respect and humility, attention to patient values, and accessibility and continuity seem to be accounted for only in part. The point is that the patients and family members interviewed for this study have contributed to our understanding of these issues in important ways. And while the Curtis findings represent an as yet to be evaluated framework for providing skilled end-of-life care, it is encouraging that in other cases interventions informed by qualitative approaches have ultimately demonstrated improved outcomes for patients. ${ }^{14}$

A previous editorial, by Aronowitz and Asch, questioned whether the time and energy devoted to end-of-life research wasn't like "cursing the darkness." ${ }^{15}$ That editorial discussed the possible futility of efforts to ascertain patient preferences for specific treatment interventions for some future point in time. Aronowitz and Asch wondered whether a qualitative approach that was "more intense, open-ended and time consuming" would yield some progress in our efforts to better understand patients and their wishes.

Indeed, patient-centered, qualitative studies have moved our thinking along. These studies point out that patients, at a minimum, are not interested in dwelling on preferences for specific future treatment interventions to the exclusion of other concerns. When asked, patients and family members have a lot to say about what good care at the end of life entails; they identify many concerns and needs that they want addressed.

How do we, as health care providers, find our way? And how do we help our patients find their way? One way out of the darkness, it seems, is for us to periodically hand over the flashlight to our patients and follow along, asking questions and listening carefully. By letting patients take the lead, light may be shed on some of our most difficult problems.-Joseph CARREse, MD, MPH, Johns Hopkins Bayview Medical Center, Baltimore, Md.

Dr. Carrese is a Robert Wood Johnson Generalist Physician Faculty Scholar, and a core faculty member of the Johns Hopkins University Bioethics Institute. 


\section{REFERENCES}

1. Bill Moyers. On our own terms: Moyers on dying, PBS, September 10-13.

2. Dying on our own terms, Time magazine, Sept. 18, 2000.

3. Tierney WM, Dexter PR, Gramelspacher GP, Perkins AJ, Zhou XH, Wolinsky FD. The effect of discussions about advance directives on patients' satisfaction with primary care. J Gen Intern Med. $2001 ; 16: 32-40$.

4. Teno J, Lynn J, Wenger $\mathrm{N}$, et al. Advance directives for seriously ill hospitalized patients: effectiveness with the patient self-determination act and the SUPPORT intervention. J Am Geriatr Soc. 1997;45:500-7.

5. Teno J, Lynn J, Phillips RS, et al. Do formal advance directives affect resuscitation decisions and the use of resources for seriously ill patients? J Clin Ethics. 1994;5:23-30.

6. Hanson LC, Tulsky JA, Danis M. Can clinical interventions change care at the end of life? Ann Intern Med. 1997;126:381-88.

7. Schneiderman LJ, Kronik R, Kaplan RM. Effects of offering advance directives on medical treatment and costs. Ann Intern Med. 1992;117:599-606.
8. Fischer GS, Arnold RM, Tulsky JA. Talking to older adult patients about advance directives. Clin Geriatric Med. 2000;16:239-54.

9. Rosenfeld KE, Wenger NS, Kagawa-Singer M. end of life decision making: a qualitative study of elderly individuals. J Gen Intern Med. 2000;15:620-5.

10. Martin DK, Thiel EC, Singer PA. A new model of advance care planning: observations from people with HIV. Arch Intern Med. 1999;159:86-92.

11. Singer PA, Martin DK, Lavery JV, Thiel EC, Kelner M, Mendelssohn DC. Reconceptualizing advance care planning from the patient's perspective. Arch Intern Med. 1998;158:879-84.

12. Curtis JR, Wenrich MD, Carline JD, Shannon SE, Ambrozy DM, Ramsey PG. Understanding physicians' skills at providing end-oflife care: perspectives of patients, families and health care workers. J Gen Intern Med. 2001;16:41-9.

13. Lynn J. Measuring quality of care at the end of life: a statement of principles. J Am Geriatr Soc. 1997;45:526-7.

14. Shain RN, Piper JM, Newton ER, et al. A randomized, controlled trial of a behavioral intervention to prevent sexually transmitted disease among minority women. N Engl J Med. 1999;340:93-100.

15. Aronowitz RA, Asch DA. Cursing the darkness: are there limits to end of life research? J Gen Intern Med. 1998;13:495-6.

JGIM Website - Visit us online today!

Please visit the JGIM World-Wide Website:

http://www.blackwellscience.com/journals 